\title{
Kyoto Protokolü Kapsamında CO2 Emisyonu ve Türkiye Üzerine Bir Olasılık Tahmini ${ }^{1}$
}

\author{
Dilara AYLA \\ Dr. Öğr. Üyesi, Recep Tayyip Erdoğan Üniversitesi, \\ Fındıklı Uygulamalı Bilimler Yüksekokulu \\ dilara.ayla@erdogan.edu.tr \\ Orcid ID: 0000-0002-0206-250X \\ Derya ALTINTAŞ \\ Dr. Öğr. Üyesi, Trabzon Üniversitesi, \\ Vakfikebir Meslek Yüksekokulu \\ daltintas@hotmail.com \\ Orcid ID: 0000-0003-1965-236X
}

\begin{abstract}
Öz
Bu çalışma, Türkiye'de 1980-2014 döneminde gerçekleşen CO2 emisyonu miktarlarını Kyoto Protokolü kapsamında öngörülen düzey değerleri çerçevesinde değerlendirerek emisyon miktarı üzerinde etkili olan değişkenlerin olasılık etkilerinin belirlenmesi amacını taşımaktadır. Değerlendirmeye alınan değişkenler doğrudan yabancı yatırımlar, dış ticaret ve gelen turist sayısından oluşmaktadır. Odak noktası Kyoto Protokolü kapsamında makul kabul edilen CO2 emisyonu miktarlarının Türkiye'deki durumu olan çalışmada, öngörülen eşik değerin altında kalınan ve bu düzeyin aşıldığ yıllar olmak üzere kategorilendirilen bağımlı kukla değişken kullanılması tercih edilmiştir. $\mathrm{Bu}$ çerçevede, ilgili eşik düzeyin altında kalınan yıllar karbon emisyonu için makul kabul edilmekte ve ülke için olumlu değerlendirilmektedir. Değiş̧kenlere ait marjinal etki hesaplamaları cebirsel olarak yapılmış ve ilgili değişkenlerin karbon emisyonu için öngörülen eşik değerin altında kalma ihtimali üzerindeki olasıllk etkisi araştırılmıştır. Analizden elde edilen bulgulara göre, doğrudan yabancı yatırım/GSYİH ve dış ticaret/GSYİH oranlarında meydana gelen azalmaların, ülkeye gelen turist sayısında gözlemlenen artışların ise $\mathrm{CO} 2$ emisyonunun eşik değerin altında kalma olasılığını arttırdığ 1 belirlenmiştir. Söz konusu tespitler, eşik değeri aşan $\mathrm{CO} 2$ emisyonunda gözlenen artışlar üzerinde etkili olabilecek değişkenlerin irdelenmesi açısından son derece önem arz etmektedir. Zira sürdürülebilir ekolojik denge için pek çok adım atılması gerekliliğgi küresel
\end{abstract}

\footnotetext{
${ }^{1}$ Makale Geliş/Kabul Tarihi: 18.11.2019 / 02.11.2020

Künye Bilgisi: Ayla, D. ve Altıntaş, D. (2021). Kyoto protokolü kapsamında $\mathrm{CO}_{2}$ emisyonu ve Türkiye üzerine bir olasılık tahmini. Kahramanmaraş Sütçü Imam Üniversitesi Sosyal Bilimler Dergisi, 18(1), 478-496. DOI: 10.33437/ksusbd.648395
} 
anlamda kabul edilmiş olmakla birlikte öngörülen tedbirlere karşı olan duyarlılık düzeyi ülkelere göre farkl1lık göstermektedir.

Anahtar Kelimeler: CO2 Emisyonu, Kyoto Protokolü, Probit.

\title{
CO2 Emissions Under The Kyoto Protocol and A Possible Prediction About Turkey
}

\begin{abstract}
The study aims to determine the possible effects of the variables affecting the amount of emissions by evaluating the actual level of $\mathrm{CO} 2$ emissions observed in the period of 1980-2014 in accordance with the values of the anticipated level within the Kyoto Protocol. The variables included in the evaluation consist of foreign direct investments, foreign trade and the number of tourists visiting. In the study which focuses on the accepted amount of $\mathrm{CO} 2$ emissions within the Kyoto Protocol, it was preferred to use the dependent dummy variable categorized as the years when the values below the predetermined threshold were obtained and the years when this value was exceeded in Turkey. In this context, the years when the values below the relevant threshold were obtained are considered reasonable for carbon emission and regarded as positive for the country. Marginal effect calculations were algebraically made and the probability effect on the prediction that the related variables would be below the threshold value anticipated for the carbon emission was searched. According to the findings obtained from the analysis, it was determined that the decreases in foreign direct investment / GDP and foreign trade / GDP ratios and the increases observed in the number of tourists visiting the country increased the probability of $\mathrm{CO} 2$ emission being below the threshold. These determinations are very important in terms of examining the variables that may affect the observed increases in $\mathrm{CO} 2$ emissions exceeding the threshold because the necessity of many steps for a sustainable ecological balance has been accepted globally, but the level of sensitivity to the anticipated measures varies among countries.
\end{abstract}

Keywords: CO2 Emissions, Kyoto Protocol, Probit.

\section{GİRIŞ}

Çevre; tüm yaşantıları boyunca canlıların etkileşim içinde oldukları fiziki, biyolojik, sosyal, ekonomik ve kültürel bir ortam olarak tanımlanmaktadır (Mevzuat Fihrist, n.d.). İnsanların giderek artan istek ve ihtiyaçlarının karşılanabilmesi sürecinde bazı bilinçsiz davranışlar ve yanlış uygulamalar nedeniyle çevrede birçok olumsuzluk meydana gelebilmektedir. $\mathrm{Bu}$ olumsuzlukların sebebinin onları meydana getiren insanlar olduğu düşünüldüğünde her ne kadar bir çelişki gibi görünse de çevre duyarlılığı, son 
yıllarda daha da yaygınlaşan bir kavram haline gelmiştir. Aslında böylece çevreye duyarlı olan insanlar, işletmeler, ekonomiler yani toplumlar doğaya ve çevreye verilen zararı giderebilmek için ona karşı sorumluluklarını yerine getirme firsatı bulmuş olacaklardır. Söz konusu çevre duyarlılığı, bilinçli toplumlar ve o toplumun önemli parçaları olan bilinçli işletmelerle mümkün olabilecektir. Örneğin Konyalılar (2018)'ın çalışmasında bahsi geçen "Sürdürülebilir Otel" denilen ya da "yeşil otel" olarak adlandırılan işletmeler, enerji ve su kullanımının azaltıldığ , daha düşük miktarlarda $\mathrm{CO} 2$ emisyonunu mümkün kılan, küresel iklim değişikliği sebebiyle çevresel tehlikelere karş1 hazırlıklı, gıda güvenliği, kuraklık ve çevre kirliliği konularında bilinçli, bu nedenle ekolojik ilkelere uygun çevre dostu yerli ve yeniden değerlendirilebilen malzemeler ile yapılmış, toplum sağlı̆̆ını ön planda tutan ve böylece yatırımcısının sosyal ve çevresel sorumluluğunu belgeleyen kurumsal turistik işletmelerdir. Bu tip işletmeler ve onların bakış açıları ile yönetsel politikaları giderek yaygınlaştırılmalıdır.

Bununla birlikte, diğer tüm endüstriler gibi, turizm de bir çevresel bozulma kaynağı olabilir. Turizm sektörünün gelişimi, yollar, havaalanları ve farklı turizm hizmetleri (tatil köyleri, restoranlar, oteller, marinalar, mağazalar ve golf sahaları gibi) büyük yatırımlar gerektirmektedir. Bu nedenle turizmin çevre üzerinde örneğin toprak erozyonu, hava ve deniz kirliliği, doğal yaşam alanı kaybı gibi büyük baskılar yaratması şaşırtıcı değildir. Başka bir ifadeyle özellikle 1980'li yıllardan itibaren büyük ilerleme gösteren turizm sektöründeki gelişmelerin çevre kirliliğine ve küresel 1sınmaya neden olması turizm sektörünün çevreye etkilerinin bilimsel çalışmalara konu olmasını gerekli kılmıştır. Özellikle turist sayısı, ampirik literatürde çevre kirliliğini önemli ölçüde etkilemiş görünmektedir (Balogh ve Jambor, 2017: 220). Türkiye’de turizm sektöründe faaliyet gösteren tesislerin giderlerini inceleyen çalışmalar, personel ve yiyecek-içecek giderlerinden sonra en önemli gider kaleminin "enerji ve yakıt" olduğu sonucuna ulaşmışlardır (Öztürk vd., 2018: 20). Turizm, dünya genelinde birçok bölgede ve ülkede yüksek büyüme potansiyeli ve ekonomik kalkınmaya büyük katkı sağlayan, hızla büyüyen bir endüstridir (Lee ve Chang, 2008: 180). Bununla birlikte turizmin, $\mathrm{CO} 2$ emisyonlarına ve dolayısıyla küresel iklim değişikliği sorununa önemli bir etkisi olan fosil yakıtların yoğun kullanımını içeren bir endüstri olduğu da göz ardı edilmemelidir (León vd., 2014: 1169).

Dünya Bankası, turizmi dünyanın en çok ve en hızlı gelişen endüstrisi olarak işaret etmektedir. Dünya Turizm ve Seyahat Konseyi’nin çalışmasının sonuçlarına göre, dünyada iş kolları $\% 8,3$, yabancı ülkelerde yapılan yatırımların $\% 9,3$ 'ü ve dünya ihracat potansiyelinin \%12'si turizm ve turizmin alt dalları çerçevesinde gerçekleştirilen ürün ve hizmetlerden oluşmaktadır (Tümbek, 2010: 185-186). Perrottet ve Benli (2016) turizmin küresel ekonomiden daha hizlı büyüdügünü ifade etmişlerdir. Ülkelerin turizm alanında gelişmeleri takip etmek 
için gösterdikleri çabalar, bu ülkelere yapılması muhtemel yabancı yatırımları da etkileyecektir. Bilindiği üzere, nasıl ki bir işletmenin rekabetteki başarısı o işletmeye yeni yatırımları çekiyorsa aynı şekilde turistik bir destinasyonun küresel turizm pazarındaki başarısının yüksek olması da yabancı turistlerin ve yatırımların bu destinasyona ve/veya ülkeye çekilmesine yardımcı olacaktır. Turizm sektörü ve bu bağlamda artması beklenen yabancı yatırımlar ise pazarlama, tanıtım ve iletişim faaliyetlerini kapsayan bütünleşik pazarlama iletişimi anlayışıyla başarıya ulaşabilecektir.

Doğrudan yabancı yatırımları (DYY) yapanlar, genellikle gittikleri ülke ile kalıcı bir ilişki kurma eğilimindedir. Dolayısıyla ülkeler arasındaki etkileşimin artışı ile birlikte teknoloji, sermaye, nitelikli iş gücü, araştırma geliştirme, uzak pazarlara erişim ve ihracat için teşvikler gibi önemli konularda küresel ekonomi çerçevesinde değişim ve gelişmeler olasıdır. Bu doğrultuda DYY'lerin ülkelerin ekonomilerinin başarısına olan katkılarının farklı alanlarda gerçekleşebileceğini söylemek mümkündür. Fakat doğrudan yabancı yatırımlardaki artışların ekolojik denge üzerinde etkisinin ne yönde olduğunun anlaşılabilmesi dikkate alınması gereken önemli bir nokta olarak karşımıza çıkmaktadır. Bu noktada söz konusu iki değişken arasındaki ilişkinin yönünün doğru olarak belirlenebilmesi, ülkelerin globalleşme sürecinin bir sonucu olarak yabancı sermayeyi teşvik edebilmek amacıyla gerçekleştirilen tüm süreçlerde çevresel düzenlemeleri, yasal ve idari çerçevede dikkate almalarıyla mümkün olacaktır. Çünkü DYY'ler ve $\mathrm{CO} 2$ emisyonu ile ilgili literatürdeki Kirlenme Hale Hipotezi'ne göre DYY'lerin giriş yaptığ 1 ülkelerde teknoloji transferi sayesinde daha yüksek teknolojiyi kullanan ülkeler, daha iyi yönetim uygulamalarına sahip olmakta ve bu durum söz konusu ülkelerde karbon emisyonu seviyesinin azalmasına katkıda bulunabilmektedir (Zeren, 2015: 6443). Kirlilik Sığınağı Hipotezi’ne göre ise doğrudan yabancı yatırımcılar çevresel maliyetlerin ihmal edildiği ülkelere yatırım yapmaktadırlar. Dolayısıyla bu hipotez ülkeler arası etkileşimin artışıla beraber DYY'lerde gözlenen artışı, $\mathrm{CO} 2$ seviyesini yükselteceğini öne sürmektedir (Copeland ve Taylor, 1994). Bunun sebebinin daha düşük maliyetlerle daha çok üretim yapmak ve daha fazla yabancı yatırımcıyı misafir etmek amacıyla ekolojik dengeyi korumak için gerekli olan önlemlerin göz ardı edilmesi olduğu söylenebilir.

DYY'ler, ülkelerin dış ticaret ile ona bağlı olarak geliştirilen büyüme ve kalkınma politikaları için önemlidir. Bu ülkeler doğrudan yatırımlarla uzun vadede iş alanlarının, GSMH'nin ve dış ticaretin arttırılmasını istemektedirler. Küreselleşme ve teknoloji gelişmeler sayesinde meydana gelen ticari serbestleşme ile ülkeler için dış ticaretin cazibesi giderek artmıştır. Ancak dış ticaret akışından kaynaklanan çevre kirliliği, özellikle küresel kirleticiler etkisiyle çevre politikalarını baltalama özelliğine sahiptir (Peters ve Hertwich, 2008: 1401). Başka bir ifadeyle, dış ticaret ekonomiler için önemli avantajlar sağlarken bazı problemleri de beraberinde getirmektedir. Örneğin dış ticaret yapan 
işletmeler satışlarıyla pazarın ve bu pazardaki payın genişlemesi, bir tarafta ekonomik büyümeyi olumlu etkilerken, diğer taraftan ticari küreselleşme ile artan rekabet baskısı, yerel işletmelerin piyasada tutunabilmek için maliyet düşürme amacıyla çevreyi olumsuz etkileyecek farklı uygulamalara yönelebilmelerine neden olabilmektedir. Nitekim dış ticaret, literatürde çevresel kalite üzerinde önemli etkileri olan temel bir unsur olarak ifade edilmektedir (Koçak, 2017: 542). Son zamanlarda yapılan çalışmalar ise $\mathrm{CO} 2$ emisyonlarının \%20 ilâ \%25'inin uluslararası ticarete konu olan ürünlerin üretiminden kaynaklandığını tespit etmiştir (Barrett vd., 2013: 451).

Kukla-Gryz (2009), yapısal eşitlik modeli kullanarak gelişmiş ve gelişmekte olan ülkelerde milli gelir, uluslararası ticaret hacmi, sivil özgürlükler endeksi değişkenlerinin hava kirliliği üzerindeki etkisini incelemiştir. Gelişmekte olan ülkelerde uluslararası ticaret ve milli gelirin hava kirliliğini dolaylı, gelişmiş ülkelerde ise milli gelirin hava kirliliğini doğrudan etkilediği sonucuna ulaşmıştır.

\section{LITERATÜR ÖZETI}

Fosil enerjinin yanmasında büyük miktarda $\mathrm{CO} 2$ salınması nedeniyle, $\mathrm{CO} 2$ emisyonları küresel 1sınmanın arkasındaki ana itici güçlerden biri olarak değerlendirilmektedir. Hava kirleticilerin (NO ve SO2) yerel etkileri olsa da, $\mathrm{CO} 2$ emisyonları küresel ölçekte sorunlara neden olmakta ve küresel isınmanın toplumsal maliyetleri zaman içinde uluslararası platformda tahakkuk etmektedir (Friedl ve Getzner, 2003: 134). Özellikle son yıllarda ekolojik dengenin bozulmasıyla ortaya çıkan hava kirliliği ve küresel ısınma hem araştırmacılar arasında hem de toplumsal platformlarda fazlaca tartışılmaya başlanan önemli konular haline gelmiştir. 1997'de imzalanan Kyoto Protokolü, imzalayan ülkeler için konuyla ilgili çok önemli bir adım olarak görülmektedir. Bu ülkeler, karbondioksit ve sera etkisine sebep olan tüm gazların emisyonunu azaltmak için çalışmaya karar vermişlerdir. Protokoldeki en önemli amaç, küresel ısınma sebebiyle artacağı düşünülen sıcaklıkların normal seviyelerde tutulmasını ve iklimlerin doğal düzeninde yaşanmasını sağlamaktır (Zeren, 2015: 6447). Fakat sera gazı emisyonlarının, Kyoto Protokolü gibi uluslararası bağlayıcılığı olan ortak çabalara rağmen dünya çapında bir artış trendinde olduğu görülmektedir (Friedl ve Getzner, 2003: 134). CO2 emisyonu ve emisyon miktarı üzerinde belirleyici etkisi olan değişkenler literatürdeki pek çok çalışmaya konu olmuştur. Kyoto Protokolü ile birlikte yakından izlenmeye başlanan $\mathrm{CO} 2$ emisyonuna yönelik olarak yapılan çalışmaların bazıları Tablo 1'de özetlenmiştir.

Tablo 1. Literatür Özeti

\begin{tabular}{|l|l|l|l|}
\hline Yazar/Yazarlar & Ülke/Dönem & Yöntem & Bulgular \\
\hline
\end{tabular}




\begin{tabular}{|c|c|c|c|}
\hline $\begin{array}{l}\text { Frankel ve Rose } \\
\text { (2005) }\end{array}$ & $\begin{array}{l}41 \\
\text { Gelişmekte } \\
\text { olan ülke ve } \\
\text { Gelişmiş } \\
\text { ülke / } 1990\end{array}$ & $\begin{array}{l}\text { Yatay kesit } \\
\text { regresyon } \\
\text { analizi }\end{array}$ & $\begin{array}{l}\text { Dış ticaretin çevre kalitesi } \\
\text { üzerindeki olumsuz etkilerine } \\
\text { dair zayı bulgular tespit } \\
\text { edilmiştir. }\end{array}$ \\
\hline $\begin{array}{l}\text { Kukla- } \quad \text { Gryz } \\
(2009)\end{array}$ & $\begin{array}{l}86 \text { düşük ve } \\
\text { düşük orta } \\
\text { gelirli } \\
\text { ülkeler/1990 } \\
\text {-2005 }\end{array}$ & $\begin{array}{l}\text { Yapısal } \\
\text { eşitlik } \\
\text { modeli }\end{array}$ & $\begin{array}{l}\text { Gelişmekte olan ülkelerde diş } \\
\text { ticaret ve ekonomik büyümenin } \\
\mathrm{CO} 2 \text { seviyesini artırdığı tespit } \\
\text { edilmiştir. }\end{array}$ \\
\hline Cialani (2013) & $\begin{array}{lr}\text { OECD } & \text { üyesi } \\
(30) & \text { ve } \\
\text { OECD Üyesi } \\
\text { Olmayan } \\
(120) & 150 \\
\text { Ülke/ } & 1960- \\
2008 & \\
\end{array}$ & $\begin{array}{l}\text { Panel Veri, } \\
\text { Westerlund } \\
\text { eşbütünleşm } \\
\text { e, ECM, } \\
\text { panel } \\
\text { nedensellik } \\
\text { analizi }\end{array}$ & 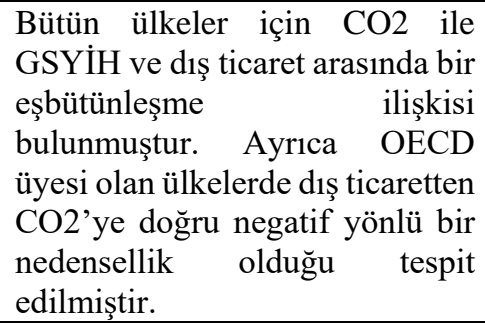 \\
\hline $\begin{array}{l}\text { Çetin ve Seker } \\
(2014)\end{array}$ & $\begin{array}{l}\text { Türkiye/198 } \\
0-2010\end{array}$ & $\begin{array}{l}\text { ARDL, Sinır } \\
\text { testi, ECM }\end{array}$ & $\begin{array}{l}\text { D1ş ticaretin çevre kirliliğini } \\
\text { arttıran bir unsur olduğu tespit } \\
\text { edilmiştir. }\end{array}$ \\
\hline $\begin{array}{l}\text { Katırcioğlu vd. } \\
\text { (2014) }\end{array}$ & $\begin{array}{l}\text { Kibris/1970- } \\
2009\end{array}$ & $\begin{array}{l}\text { ARDL ve } \\
\text { Granger } \\
\text { nedensellik } \\
\text { testi }\end{array}$ & $\begin{array}{l}\mathrm{CO} 2 \text { ve turizmin eşbütünleşik } \\
\text { olduğu ve turizmin CO2 } \\
\text { üzerindeki etkisinin pozitif } \\
\text { olduğu bulunmuştur. Ayrıca } \\
\text { uzun dönemde turizmden } \\
\mathrm{CO} 2 \text { 'ye doğru tek yönlü bir } \\
\text { nedensellik ilişkisi tespit } \\
\text { edilmiştir. }\end{array}$ \\
\hline $\begin{array}{l}\text { Katırcioğlu } \\
(2014)\end{array}$ & $\begin{array}{l}\text { Türkiye/196 } \\
0-2010\end{array}$ & ARDL & $\begin{array}{l}\text { Turizm ve CO2'nin uzun } \\
\text { dönemde birlikte hareket ettiği } \\
\text { ve uzun dönemde turizmin } \\
\mathrm{CO} 2 \text { 'yi pozitif etkilediği } \\
\text { bulunmuştur. Ayrıca Türkiye'de } \\
\text { turizmde yaşanan gelişmelerin } \\
\text { sadece gelir ve enerji tüketimini } \\
\text { değil CO2 seviyesini de önemli } \\
\text { ölçüde artırdığ1 sonucuna } \\
\text { ulaşılmıştır. }\end{array}$ \\
\hline León vd. (2014) & $\begin{array}{l}14 \text { gelişmiş } \\
\text { ve } 31 \text { az } \\
\text { gelişmiş } \\
\text { ülke/1998- } \\
2006\end{array}$ & GMM-FGLS & $\begin{array}{l}\text { Gelişmiş ve az gelişmiş ülkelerde } \\
\text { turizmin CO2 seviyesini artırdığ } 1 \\
\text { tespit edilmekle birlikte, geliş̧ş̧̧̧ } \\
\text { ülkelerde bu etkinin az gelişmiş } \\
\text { ülkelere göre daha fazla olduğu } \\
\text { bulunmuştur. }\end{array}$ \\
\hline
\end{tabular}




\begin{tabular}{|c|c|c|c|}
\hline Solarin (2014) & $\begin{array}{l}\text { Malezya/197 } \\
\text { 2-2010 }\end{array}$ & $\begin{array}{l}\text { ARDL ve } \\
\text { Granger } \\
\text { nedensellik } \\
\text { testi }\end{array}$ & $\begin{array}{l}\text { CO2 ile turizm ve ekonomik } \\
\text { büyümenin uzun dönemde } \\
\text { eşbütünleşik olduğu tespit } \\
\text { edilmişir. Ayrica uzun dönemde } \\
\text { turizmden CO2'ye doğru tek } \\
\text { yönlü pozitif bir nedensellik } \\
\text { ilişkisi bulunmuştur. Kisa } \\
\text { dönemde ise turizm ve CO2 } \\
\text { arasında çift yönlü bir } \\
\text { nedensellik olduğu sonucuna } \\
\text { ulaşılmıştır. }\end{array}$ \\
\hline $\begin{array}{l}\text { Farhani ve Ozturk } \\
\text { (2015) }\end{array}$ & $\begin{array}{l}\text { Tunus/1971- } \\
2012\end{array}$ & $\begin{array}{l}\text { ARDL ve } \\
\text { Granger } \\
\text { nedensellik } \\
\text { testi }\end{array}$ & $\begin{array}{l}\text { CO2, ekonomik büyüme, ticari } \\
\text { dışa açklı ve kentleşmenin } \\
\text { uzun dönemde ilişkili olduğu } \\
\text { tespit edilmiştir. Ekonomik } \\
\text { büyüme ve } \mathrm{CO} 2 \text { arasında pozitif } \\
\text { yönlü bir ilişki bulunmuştur. } \\
\text { Ayrıca uzun dönemde ticari dışa } \\
\text { açıklı ve kentleşmenin CO2 } \\
\text { üzerindeki etkisi pozitiftir. } \\
\text { Uzun dönemde kentleşmeden } \\
\text { CO2'ye doğru tek yönlü bir } \\
\text { nedensellik ilişkisi, ticari dişa } \\
\text { açılık ve CO2 arasinda ise çift } \\
\text { yönlü bir nedensellik ilişkisi söz } \\
\text { konusudur. Kısa dönemde ise } \\
\text { kentleşmeden CO2'ye ve } \\
\text { CO2'den ticari dişa açılıı̆ga } \\
\text { doğru tek yönlü nedensellik } \\
\text { ilişkisi bulunmuştur. }\end{array}$ \\
\hline $\begin{array}{l}\text { Ibrahim ve Law } \\
\text { (2016) }\end{array}$ & $\begin{array}{l}40 \text { Safra alt1 } \\
\text { Afrika } \\
\text { Ülkesi/2000- } \\
2010\end{array}$ & $\begin{array}{l}\text { Dinamik } \\
\text { panel veri } \\
\text { GMM }\end{array}$ & 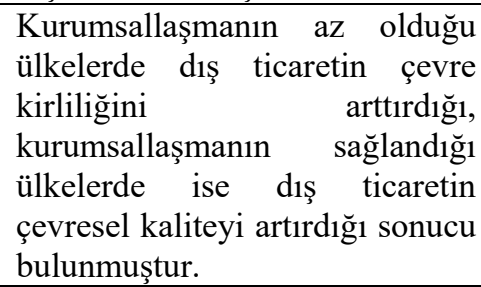 \\
\hline Ng vd. (2016) & $\begin{array}{l}\text { Malezya/ } \\
\text { 1981-2011 }\end{array}$ & $\begin{array}{l}\text { ARDL ve } \\
\text { Granger } \\
\text { nedensellik } \\
\text { testi } \\
\text { (VECM) }\end{array}$ & $\begin{array}{l}\mathrm{CO} 2 \text { ile turizm ve doğrudan } \\
\text { yabanc1 yatımların eşbütünleşik } \\
\text { olduğu ve uzun dönemde turizm } \\
\text { ve doğrudan yabancı yatırımların } \\
\mathrm{CO} 2 \text { seviyesini artırdığı tespit } \\
\text { edilmiştir. Ayrıca turizmden } \\
\mathrm{CO} 2 \text { ye doğru tek yönlü bir } \\
\text { nedensellik ilişkisi bulunmuştur. }\end{array}$ \\
\hline
\end{tabular}




\begin{tabular}{|c|c|c|c|c|}
\hline $\begin{array}{l}\text { Shahbaz } \\
\text { (2016) }\end{array}$ & vd. & $\begin{array}{l}\text { Malezya/ } \\
\text { 1970:Q1- } \\
\text { 2011:Q4 }\end{array}$ & $\begin{array}{l}\text { Bayer- } \\
\text { Hanck } \\
\text { eşbütünleşm } \\
\text { e analizi, } \\
\text { ARDL ve } \\
\text { VECM } \\
\text { Granger } \\
\text { nedensellik } \\
\text { testi }\end{array}$ & $\begin{array}{l}\text { Ekonomik büyümenin } \mathrm{CO} 2 \\
\text { üzerinde önemli bir katkıs1 } \\
\text { olduğu tespit edilmiştir. Ticari } \\
\text { dışa açıklığın CO2'yi artırdığ1, } \\
\text { kentleşmenin ise CO2 üzerindeki } \\
\text { etkisinin U şeklinde olduğu } \\
\text { bulunmuştur. } \\
\text { kentleşmeden CO2'ye doğru tek } \\
\text { yönlü bir nedensellik iliş̧kisi söz } \\
\text { konusudur. }\end{array}$ \\
\hline $\begin{array}{l}\text { Tandoğan } \\
\text { Genç (2016) }\end{array}$ & ve & $\begin{array}{l}\text { Türkiye/198 } \\
\text { 0-2011 }\end{array}$ & $\begin{array}{l}\text { Engle- } \\
\text { Granger } \\
\text { eşbütünleşm } \\
\text { e ve ECM }\end{array}$ & $\begin{array}{l}\text { Turizm ve CO2'nin eşbütünleşik } \\
\text { olduğu ve aralarında çift yönlü } \\
\text { bir nedensellik ilişkisi olduğu } \\
\text { tespit edilmiştir. }\end{array}$ \\
\hline $\begin{array}{l}\text { Değer ve } \\
(2017)\end{array}$ & Pata & $\begin{array}{l}\text { Türkiye/ } \\
\text { 1971-2012 }\end{array}$ & $\begin{array}{l}\text { Toda- } \\
\text { Yamamoto, } \\
\text { Hacker- } \\
\text { Hatemi ve } \\
\text { Hatemi-J } \\
\text { nedensellik } \\
\text { testleri }\end{array}$ & 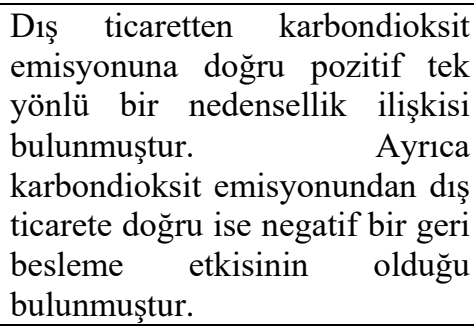 \\
\hline Karış (2017) & & $\begin{array}{l}\text { Türkiye/ } \\
\text { 1960-2013 }\end{array}$ & $\begin{array}{l}\text { Toda- } \\
\text { Yamamoto } \\
\text { nedensellik } \\
\text { testi }\end{array}$ & $\begin{array}{l}\text { Ekonomik büyümeden CO2'ye } \\
\text { doğru tek yönlü pozitif bir } \\
\text { nedensellik ilişkisi bulunmuştur. }\end{array}$ \\
\hline $\begin{array}{l}\text { Paramati } \\
\text { (2017) }\end{array}$ & vd. & $\begin{array}{l}28 \text { Doğu ve } \\
\text { Batı Avrupa } \\
\text { Birliği } \\
\text { ülkesi/1991- } \\
2013\end{array}$ & $\begin{array}{l}\text { Westerlund } \\
\text { panel } \\
\text { eşbütünleşm } \\
\text { e, FMOLS } \\
\text { ve } \\
\text { Heterogeneo } \\
\text { us panel } \\
\text { nedensellik } \\
\text { testi }\end{array}$ & $\begin{array}{l}\text { Uzun dönemde turizm, CO2, } \\
\text { ekonomik büyüme, doğrudan } \\
\text { yabancı yatırımlar ve dış ticaretin } \\
\text { ilişkili olduğu bulunmuştur. } \\
\text { Turizm CO2 seviyesini Doğu } \\
\text { Avrupa Birliği ülkelerinde } \\
\text { yükseltirken, Batı Avrupa Birliği } \\
\text { ülkelerinde azaltmaktadır. Kısa } \\
\text { dönemde Doğu Avrupa Birliği } \\
\text { ülkelerinde turizmden CO2'ye } \\
\text { doğru, Batı Avrupa Birliği } \\
\text { ülkelerinde CO2'den turizme } \\
\text { doğru tek yönlü bir nedensellik } \\
\text { ilişkisi tespit edilmiştir. }\end{array}$ \\
\hline Bekar (2018) & & $\begin{array}{l}\text { Türkiye/197 } \\
\text { 7-2014 }\end{array}$ & $\begin{array}{l}\text { Toda- } \\
\text { Yamamoto, } \\
\text { Dolado- } \\
\text { Lütkepohl } \\
\text { VAR } \\
\text { nedensellik }\end{array}$ & $\begin{array}{l}\text { CO2'den ekonomik büyümeye } \\
\text { doğru tek yönlü pozitif bir } \\
\text { nedensellik ilişkisi tespit } \\
\text { edilmiştir. }\end{array}$ \\
\hline
\end{tabular}




\begin{tabular}{|c|c|c|c|}
\hline $\begin{array}{l}\text { Okutan ve Yamak } \\
\text { (2018) }\end{array}$ & $\begin{array}{l}\text { Türkiye/196 } \\
0-2013\end{array}$ & ARDL & $\begin{array}{l}\text { CO2 ve ekonomik büyüme } \\
\text { arasında ters U şeklinde ilişki } \\
\text { olduğunu ortaya koyan Çevresel } \\
\text { Kuznet eğrisinin geçerli olduğu } \\
\text { tespit edilmiştir. Ayrıca } \\
\text { Türkiye'de kişi başına düşen } \\
\text { uzun dönem gelir en az } 12.901 \\
\text { Amerikan dolarına ulaştığında } \\
\text { CO2 seviyesinin en üst düzeye } \\
\text { çıtığı tespit edilmiştir. }\end{array}$ \\
\hline
\end{tabular}

\section{YÖNTEM}

Analizde Kyoto Protokolü kapsaminda öngörülen karbon emisyonu miktarının aşııı aşılmadığı yıllar dikkate alınarak oluşturulan bağımlı değişken kuklasına yer verilmesi nedeniyle tercih edilen ekonometrik yöntem Probit analizi olarak belirlenmiştir.

Probit modeli, doğrusal olmayan ancak normal birikimli dağılım fonksiyonunun tersi alınarak doğrusal hale getirilebilen ve böylece olasılık değerinin " 0 " ve " 1 " arasında değer almasının sağlandığı bir modeldir (Gujarati, 1988: 707).

Analizde olasılık tahmini yapan değişkenlerin doğrusal bir fonksiyonu olan Z değişkeni:

$$
Z=\beta_{1}+\beta_{2} X_{2}+\cdots+\beta_{k} X_{k}
$$

Şeklinde tanımlanmaktadır. $F(Z)$ ise normal birikimli dağılım fonksiyonunun tersi alınarak standartlaştırılmış fonksiyonu ifade eder. $\mathrm{Bu}$ fonksiyon, Z'nin herhangi bir değeri için bir olayın gerçekleşmesi olasılığını ifade etmektedir (Dougherty, 2007: 10).

\section{BULGULAR}

Çalışmada Kyoto Protokülü'ne 24 Mayıs 2004 tarihinde dâhil olan Türkiye'de 1980-2014 döneminde gerçekleşen karbon emisyonu miktarı üzerinde etkili olan çeşitli değişkenler kullanılarak sürdürülebilir hava kirliliğinin azaltılması kapsamında bir değerlendirme yapılması amaçlanmaktadır. Protokol gereği 1990 yılı karbon emisyonu miktarının \%5 azaltılması gerekliliği çerçevesinde eşik değer belirlemesi yapılarak bu değerin altında kalınan yıllara "1" ve eşik değerin aş1ldığ y1llara " 0 " değeri verilerek kukla değişken oluşturulmuştur. Buna göre Türkiye 1980 yılından 1989 yılına kadar makul kabul edilen emisyon miktarına sahip iken 1989-2014 yılına kadar olan süreçte ise eşik değeri aşmış durumdadır. 
Çalışmanın odak noktası CO2 emisyonunun kabul edilebilir düzeyde olma olasılığını etkileyen değişkenlerin etki düzeylerinin belirlenmesi üzerinedir. Yıllık veriler kullanılarak uygulanan analiz, ilk olarak literatürde CO2 emisyonu üzerinde etkili olduğu kabul edilen 6 (Nihai tüketim, DYY, GSYİH, dış ticaret, kentsel nüfus ve gelen turist sayısı) değişken ile başlatılmış ancak çeşitli kombinasyonlar altında çözümlemeler yapıldıktan sonra çoklu doğrusal bağıntı problemi içermeyen ve istatistiki olarak anlamlı olduğu tespit edilen 3 (doğrudan yabanc1 yatırımlar, dış ticaret ve gelen turist sayısı) değişken ile sürdürülebilmiştir. Söz konusu değişkenlere ait veri setlerine Worldbank ve TÜİK veri tabanlarından ulaşılmıştır. Çalışmada kullanılan bağımlı değişkenin nitel olması Probit tahmin modelinin tercih edilmesinde belirleyici olmuş ve değişkenler modele dâhil edilmeden önce gerekli logaritmik ve fark işlemleri gerçekleştirilmiştir. Analizde kullanılan değişkenler ve ilgili açıklamalar Tablo 2 'de raporlanmıştır.

Tablo 2. Analiz Değişkenleri ve İstatistiki Açıklamalar

\begin{tabular}{|c|c|c|c|c|c|c|}
\hline \multicolumn{2}{|c|}{ DEĞISTKENLER } & \multicolumn{5}{|c|}{ AÇIKLAMALAR } \\
\hline \multicolumn{2}{|l|}{$\mathrm{CO} 2 \mathrm{~K}$} & \multicolumn{5}{|c|}{ Karbon Emisyonu Kukla Değişkeni (Kişi Başına Metrik Ton) } \\
\hline \multicolumn{2}{|l|}{ LGT } & \multicolumn{5}{|c|}{ Logaritmik Gelen Turist Sayısı } \\
\hline \multicolumn{2}{|l|}{ LDT/GSYIH } & \multicolumn{5}{|c|}{ Logaritmik Dış Ticaret/GSYİH (\%) Oranı } \\
\hline LFDI/GSYİH & & \multicolumn{5}{|c|}{ Logaritmik Doğrudan Yabancı Yatırımlar/GSYİH (\%) Oranı } \\
\hline \multicolumn{7}{|c|}{ İstatistiki Göstergeler } \\
\hline Seri & Gözlem & Ortalama & $\begin{array}{l}\text { St } \\
\text { Sap. }\end{array}$ & Min. & Maks. & $\begin{array}{l}\text { Jarque- } \\
\text { Bera } \\
\end{array}$ \\
\hline LGT & \multirow{3}{*}{35} & 15.9005 & 1.0705 & 13.8713 & 17.4220 & $\begin{array}{c}1.9855 \\
(0.3706)\end{array}$ \\
\hline LDT/GSYIH & & -0.9396 & 0.2722 & -1.7667 & -0.5984 & $\begin{array}{c}8.1184 \\
(0.0173) \\
\end{array}$ \\
\hline LFDI/GSYİH & & -0.6848 & 1.1399 & -3.6433 & 1.2957 & $\begin{array}{c}0.7097 \\
(0.7013)\end{array}$ \\
\hline
\end{tabular}

Çalışmada kullanılacak olan değişkenlerin zaman seyri grafikleri Şekil 1'de gösterilmiştir.
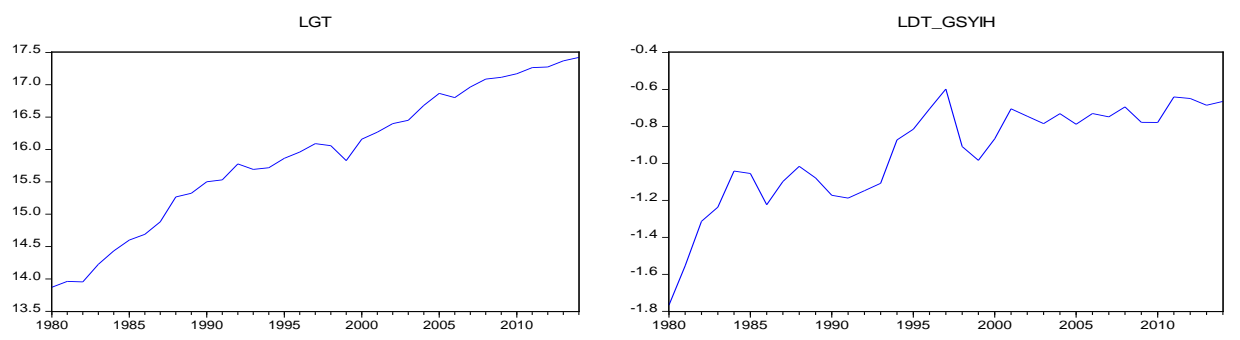


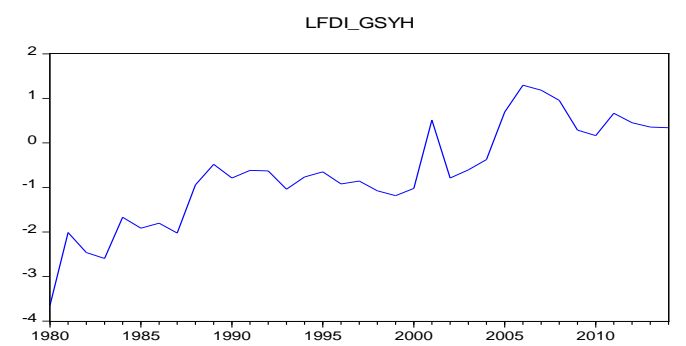

Şekil 1. Değişkenlerin Grafiksel Gösterimleri

Zaman serilerine uygulanan Probit modellerine ait tahminlemelerde model değişkenlerinin durağan oldukları seviyelerde koşturulması gerekliliği vardır. $\mathrm{Bu}$ nedenle ilgili olasılık tahmini yapılmadan önce serilerin durağan oldukları seviyelerin belirlenmesi amacıyla ADF (Genişletilmiş Dickey-Fuller) durağanlık analizinden yararlanılmıştır. Akaike (AİC) bilgi kriteri ve maksimum 8 gecikme uzunluğu kapsamında uygulanan ADF test sonuçları Tablo 3 'te özetlenmiştir.

Tablo 3. Durağanlık Analizi Sonuçları

\begin{tabular}{|l|l|l|l|l|l|l|}
\hline & \multicolumn{2}{|l|}{ ADF (Sabitsiz) } & \multicolumn{2}{l|}{ ADF (Sabitli) } & \multicolumn{2}{l|}{ ADF (Sabitli ve } \\
Trendli)
\end{tabular}

Tablo 3'te belirtilen durağanlı analizi sonuçlarına göre, LDT/GSYİH ve LFDI/GSYİH değişkenlerinin seviyesinde; LGT değişkenin ise 1. farkında durağan olduğu tespit edilmiştir. Söz konusu tespitin ardından Quadratic Hill Climbing algoritması ve Huber-White kriteri kullanılarak oluşturulan olasılık tahmini aşamasına geçilmiştir. Bu kapsamda ilgili modellere ait tahmin sonuçları Model A ve Model B şeklinde gruplandırılarak aşağıda rapor edilmiştir.

Tablo 4. Model A Tahmin Sonuçları

\begin{tabular}{|l|l|l|l|l|l|}
\hline Değişken & Katsayı & $\begin{array}{l}\text { Std. } \\
\text { Hata }\end{array}$ & $\begin{array}{l}\text { z- } \\
\text { İstatistiği }\end{array}$ & Olasılık & $\begin{array}{l}\text { Marjinal } \\
\text { Etki } \\
\text { KatsayıSı }\end{array}$ \\
\hline C & -9.1336 & 2.3963 & -3.8116 & 0.0001 & - \\
\hline DLGT & 6.1726 & 2.6505 & 2.3288 & 0.0199 & 0.0117 \\
\hline
\end{tabular}




\begin{tabular}{|l|l|l|l|l|l|}
\hline LDT/GSYİH & -7.3478 & 2.0975 & -3.5031 & 0.0005 & -0.0140 \\
\hline LR İstatistiği & $\begin{array}{l}21.8787 \\
(0.0000)\end{array}$ & \multicolumn{3}{|c|}{ Wald F-İstatistiği } & $\begin{array}{l}6.3570 \\
(0.0049)\end{array}$ \\
\hline McFadden R2 & 0.5897 & \multicolumn{3}{|c|}{ LM Test } & $\begin{array}{l}0.4426 \\
(0.5059)\end{array}$ \\
\hline Log likelihood & -7.6109 & \multicolumn{3}{|c|}{. }
\end{tabular}

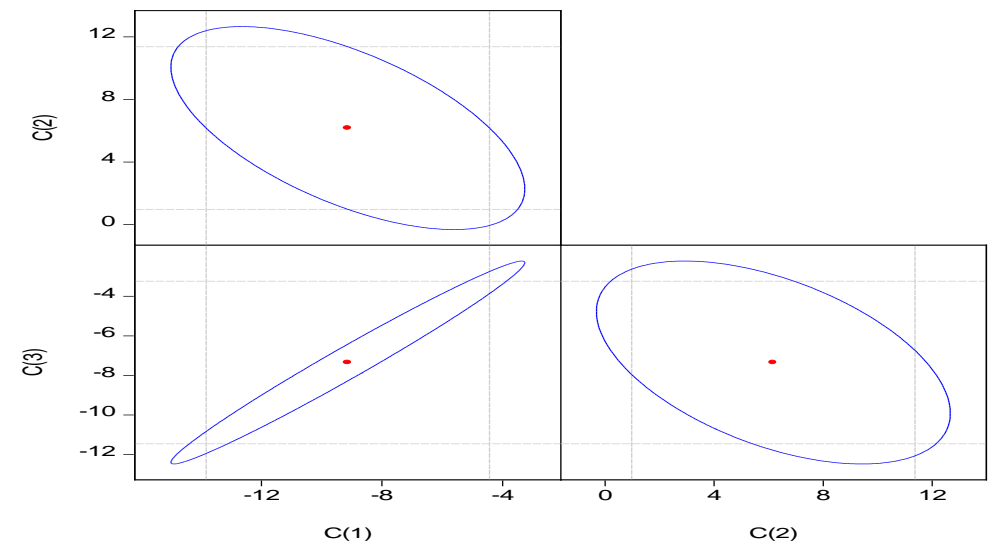

Şekil 2. Model A Güven Aralıkları

Probit modelleri değişkenlerin katsayı yorumuna imkân vermediği için bağımsız değişkenlerin bağımlı kukla değişkenin "1" değerini alma olasılı̆̆ 1 üzerindeki etki katsayıları marjinal etki hesaplaması yapılarak elde edilmiştir. Buna göre, Tablo 5'te belirtilen ve gelen turist sayısinı ifade eden DLGT değişkeni \%1 artarsa kukla değişkenin "1" değerini alma olasıllğ 1 \%1,17 artmaktadır. Başka bir ifadeyle, ardışık iki yıllık turist sayısının farkının artması yani turist sayılarındaki dalgalanmanın artması bağımlı değişkenin 1 değerini alması olasılığını arttırmaktadır. Dış Ticaret/GSYİH (\%) oranını ifade eden LDT/GSYIH değişkeni \%1 artarsa ise bağımlı değişkenin 1 değerini alma olasılığ $\quad\left(7,3478^{*} 0,0019 * \log 1,01=0,00006032\right) \quad \% 0,006$ azalmaktadır. $\mathrm{Bu}$ değişkenin logaritmik olması nedeniyle değişkene ait marjinal etki katsayısı değişkenin 10 katına çıkması halinde bağımlı değişkenin 1 değerini alma olasılığının \%1,4 azalacağı şeklinde yorumlanmalıdır. Söz konusu sonuçlara göre gelen turist sayısındaki artışlar Kyoto protokolü kapsamında öngörülen karbon emisyonu miktarını olumlu yönde etkilemektedir. $\mathrm{Bu}$ durum eğitim ve kültür düzeyi ile açıklanabilecektir. Dış Ticaret/GSYIH (\%) oranı ile emisyonu miktarı arasındaki olumsuz etkileşim ise emisyon gazı salınımını arttıran teknolojilerin gereken düzeyde engellenmemesi ile açıklanabilir. 
Model A kapsamında elde edilen tahmin sonuçlarına göre, Mc Fadden R2, Wald ve LR istatistiklerinin çözümleme kapsamında yeterli olduğu görülmüştür. Ayrıca Davidson ve MacKinnon (1993) tarafindan da kullanıldı̆̆ı şekliyle varyans sınaması için LM testi kullanılmış ve sonuçlara ait olasılık değerinin 0,05 ’ten büyük olduğu gözlenmiştir.

Tablo 6. Model B Tahmin Sonuçları

\begin{tabular}{|c|c|c|c|c|c|}
\hline Değişken & Katsayı & $\begin{array}{l}\text { Std. } \\
\text { Hata }\end{array}$ & $\begin{array}{l}\text { z- } \\
\text { İstatistiği }\end{array}$ & Olasılık & $\begin{array}{l}\text { Marjinal Etki } \\
\text { Katsayısı }\end{array}$ \\
\hline C & -7.9250 & 2.0106 & -3.9417 & 0.0001 & - \\
\hline LFDI/GSYİH & -3.6388 & 0.7744 & -4.6991 & 0.0000 & -0.0069 \\
\hline LDT/GSYIH & -3.2282 & 1.5684 & -2.0583 & 0.0396 & -0.0061 \\
\hline LR İstatistiği & $\begin{array}{l}33.0072 \\
(0.0000)\end{array}$ & \multicolumn{3}{|c|}{ Wald F-İstatistiği } & $\begin{array}{l}13.2118 \\
(0.0001)\end{array}$ \\
\hline McFadden R2 & 0.8272 & \multirow{2}{*}{\multicolumn{3}{|c|}{ LM Test }} & 0.0846 \\
\hline Log likelihood & -3.4481 & & & & $(0.7712)$ \\
\hline
\end{tabular}

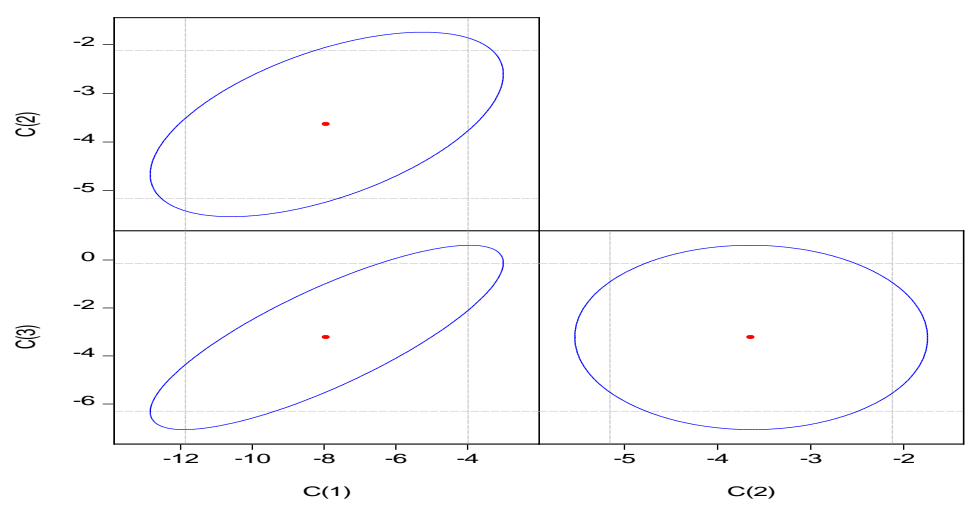

Şekil 2. Model B Güven Aralıkları

Tablo 5'te sunulan sonuçlar değerlendirildiğinde ise Model B için hesaplanan McFadden R2 değerinin daha yüksek olması bu modelin açıklayıcılık gücünün daha yüksek olduğunu göstermiştir. Modele ait Wald testi ve LR istatistiği sonuçları da ilk modelde olduğu gibi model değişkenlerinin bütün olarak anlamlı olduğunu göstermekle birlikte modelin uyum iyiliğinin yeterli bulunduğunu ifade etmektedir. Ek olarak uygulanan LM testine ait sonuçlar da Model B'nin değişen varyans sorunu içermediğini göstermiştir.

Model B kapsamında elde edilen bulgulara göre, DYY/GSYIH (\%) oranını ifade eden LFDI/GSYİH değişkeni \%1 artarsa bağımlı değişkenin 1 değerini 
alma olas1lı̆̆ $1(3,6388 * 0,0019 * \log 1,01=0,00002988) \% 0,0029$ azalmaktadır. Söz konusu değişkenin logaritmik olması nedeniyle değişkene ait marjinal etki katsayısı değişkenin 10 katına çıkması halinde bağımlı değişkenin 1 değerini alma olasıllığının \%0,7 azalacağını ifade etmektedir. LDT/GSYIHH değişkenin bu model kapsamında değerlendirilmesi durumunda 10 katına çıkan bu oranın bağımlı değişkenin 1 değerini alma olasılı̆̆ını \%0,6 azaltacağı yorumu yapılabilecektir. İlgili yorumun \%1 bazında yapılması halinde ise LDT/GSYIH değerinin \%1 artması halinde bağımlı değişkenin 1 değerini alma olasıllğının $(3,2282 * 0,0019 * \log 1,01=0,000026505) \quad \% 0,0027$ azalacağ 1 söylenebilecektir. LDT/GSYIH değişkeni için elde edilen sonuçlar katsayı olarak düşük olsa da Model A ile tutarlılık göstermektedir. Model B kapsamında elde edilen bu sonuçlara göre LFDI/GSYIH oranı ile emisyonu miktarı arasındaki olumsuz etkileşim ise ülkemize yönelen doğrudan yabancı yatırımların teknoloji ağırlıklı olması ve zararlı gaz salınımı, çevre duyarlılığı gibi konularda yeterli düzeyde bir kısitlama altında olmamalarından kaynaklanabilecektir.

\section{SONUÇ}

İklim değişikliği ve küresel ısınmayla mücadele konusunda şimdiye kadarki etki alanı en geniş uygulama olan Kyoto Protokolü, 1992 UNFCCC Konferansı'nda Birleşmiş Milletler İklim Değişikliği Çerçeve Sözleşmesi (United Nations Framework Convention on Climage Change - UNFCCC) ile oluşturulmuş ve 21 Mart 1994 tarihinden itibaren yürürlüktedir (T.C. Dışişleri Bakanlığ 1, n.d.). Protokol, küresel ısınmanın varlığ ve buna sebebiyet veren $\mathrm{CO} 2$ üretiminin insan kaynaklı olduğu varsayımı üzerinden hareketle ülkeleri sera gazı emisyonlarını azaltma konusunda yönlendirmektedir. Protokol'e göre ülkeler, 1990 yılını baz almak kaydıyla 2008-2012 yılları arasında emisyonlarını \%5 oranında azaltmak için çalışmayı taahhüt etmişlerdir. Kyoto Protokolü'nün yürürlükte kalma süresi 2020 yılında sona erecektir ve günümüzde Kyoto'nun yerini alacak yeni bir uluslararası protokolün çalışmaları yürütülmektedir. $\mathrm{Bu}$ kapsamda iklim değişikliğinin etkilerini azaltmak ve uyum sağlamak için farklı uygulamalar geliştirilmeye ve önlemler alınmaya çalışılmaktadır. Yapılan araştırmalar sonucunda iklim değişikliğinden etkilenmemizin asgari düzeyde olması için küresel ısınmanın 1990 yılı baz alındığında 2100 yılında 2 santigrat derece ile sınırlandırılması gerektiği belirlenmiş ve bu karar COP (Taraftarlar Konferans1) üyesi ülkeler tarafından onaylanmıştır (Bitlis, 2021).

Kyoto Protokolü ile birlikte üye ülkelere ekolojik dengenin korunması ve $\mathrm{CO} 2$ emisyonu ile ilgili uyulması gereken belirli kurallar ve kısıtlamalar getirilmiştir. Çevre kirliliğine neden olan diğer etkenlerin yanı sıra dış ticaret politikaları da bu kurallar kapsamında değerlendirilip çevre kirliliğinin azaltılması konusunda kararlı olan ülkeler tarafından dikkatlice ele alınıp düzenlemeler yapılmaktadır. Türkiye de 2009 'da imzaladığı ve sera gazı salınımını azaltmayı hedefleyen 
Kyoto Protokolü ile bu konudaki tavrını ortaya koymaktadır (Kanberoğlu vd., 2017: 275).

$\mathrm{Bu}$ çalışmanın amacı, Kyoto protokolü kapsamında çevresel kirliliğin önlenmesinin sürdürülebilirliği için CO2 emisyonu ile bağlantılı turizm, DYY ve dış ticaret değişkenleri açısından probit modelleme yöntemi ile tahminde bulunulmasıdır. Kyoto Protokülü'nde öngörülen karbon emisyonu taahhüdü kapsamında oluşturulan analizde Türkiye'de 1980-2014 döneminde gerçekleşen $\mathrm{CO} 2$ emisyonu üzerinde etkili olduğu kabul edilen DYY/GSYIH, diş ticaret/GSYİH ve gelen turist sayısı değişkenleri kullanılarak olasılık tahmini yapılmıştır. Probit modelinin kullanıldığ 1 bu çalışmada ilgili modelin değişkenlerin katsayı yorumunu içermemesi nedeniyle cebirsel olarak yapılan marjinal etki hesaplamalarına da yer verilmiştir. Yapılan analiz sonucunda DYY/GSYIH ve dış ticaret/GSYİH oranlarında meydana gelen azalmaların, ülkeye gelen turist sayısında gözlemlenen artışların $\mathrm{CO} 2$ emisyonunun eşik değerin altında kalma olasılığını arttırabileceği bulgusuna ulaşılmıştır. İlgili değişkenlerden gelen turist sayısına ait marjinal etki katsayının diğer değişkenlere oranla daha yüksek olması dikkat çekmektedir. Turist sayısında yaşanan artışa paralel olarak niteliksel anlamda artış gösteren tüketim bilinci bu sonucun sebebini oluşturabilecektir. Ayrıca bu durumun küreselleşme süreci ile hız kazanan turizmin, ekonomiyi ve ekonomik büyümeyi olumlu yönde etkileyen en önemli sektörlerden biri olmasından da kaynaklanabileceği düşünülmektedir. Aslında turizmin büyümesinde en büyük sorun, fosil yakıtların yanması ile bağlantılı olan ulaştırma ile enerji tüketimi bağımlılığının artması ve bu artışın sera gazı emisyonu seviyesini etkilemesine neden olmasidır (Balogh ve Jambor, 2017: 219). Ayrıca turizm sektörü, enerji sektörünün yanı sıra yine önemli miktarda enerji ve doğal kaynak kullanan taşımacıllk şirketleri, seyahat acenteleri, tarım, gıda, restoran gibi büyüklü küçüklü birçok farklı sektör ile bağlantılı işletmeleri kapsayan ayrıcalıklı bir sektördür. Bu nedenle turizm sektörünün sürdürülebilir gelişme açısından diğer sektörlerle olan karşılıklı etkileşiminin detaylı bir şekilde analiz edilmesi, gerek turizm endüstrisinde gerekse ekonominin diğer sektörlerinde etkin politikaların oluşturulması açısından önem arz etmektedir (Bölük ve Karkacıer, 2019: 391-392). Bu amaçla sürdürülebilirlik açısından turizm sektörünün de enerjiye bağımlılığını azaltacak, daha temiz ve yeni enerji teknolojilerine, bu teknolojileri hayata geçirmemizi sağlayacak turizmle ilgili AR-GE çalışmalarına yatırım yapılması gerekmektedir. Ekolojik dengenin göz önünde bulundurulduğu, günümüzde sayısı giderek artan yeşil oteller bu doğrultuda atılmış önemli adımlar olarak karşımıza çıkmaktadır.

Ekonomiler için diş kaynak, gelişmiş teknoloji, entelektüel sermaye, yeni yönetim ve organizasyon sistemleri, modern pazarlama uygulamaları ve ihracat imkânı gibi faydaları ile temel bir unsur olarak dikkat çeken DYY'lerin CO2 emisyonu ile ilişkisinde ise ev sahibi ülkeler yasal düzenlemeler ve kontroller 
yardımıyla doğal kaynaklarını kötü kullanan DYY'leri belirleyerek sistemlerinden eleyebilirlerse; çevreyi koruyucu standartlar belirleyebilir ve yükümlülükleri ve zararlarının tazminatları için sisteme dâhil olan işletmelerini kurumsallaştırabilirlerse küresel çapta çevresel kirliliğin önlenmesi noktasında önemli adımlar atmış olurlar.

Dış ticaretin $\mathrm{CO} 2$ emisyonu ile ilişkisi değerlendirildiğinde dışa açık, küreselleşmeyi benimsemiş ülkelerin, politikaları ve uygulamalarıyla işletmeleri, $\mathrm{CO} 2$ ve benzeri zararlı sera gazı emisyonlarını azaltmak için çevre dostu ve verimli teknolojiler kullanma konusunda cesaretlendirmeleri ve desteklemeleri gerekmektedir.

\section{KAYNAKÇA}

Balogh, J. M. and Jámbor, A. (2017). Determinants of CO2 emission: A global evidence. International Journal of Energy Economics and Policy, 7(5), 217-226.

Barrett, J., Peters, G., Wiedmann, T., Scott, K., Lenzen, M., Roelich, K. and Le Quéré, C. (2013). Consumption-Based GHG emission accounting: A UK case study. Climate Policy, 13(4), 451-470. https://doi.org/10.1080/14693062.2013.788858

Bekar, A. S. (2018). The relationship between $\mathrm{CO} 2$ emission and economic growth in Turkey: 1977-2011, Uluslararasi Iktisadi ve Idari Incelemeler Dergisi, 193-206. https://doi.org/10.18092/ulikidince.428059

Bitlis, M. (2021, Mart 12). İklim değişikliği ve karbon yönetimi. Escarus. http://www.escarus.com/tr/iklim-degisikligi-ve-karbon-yonetimi

Bölük, G. ve Karkacıer, O. (2019). Türkiye'de turizm sektörünün enerji ve toplulaştırılmış diğer sektörler ile yapısal analizi: Girdi-Çıktı modeli analizi, Uluslararası Yönetim İktisat ve Iş̧letme Dergisi, 15(2), 390-408. https://doi.org/10.17130/ijmeb.2019252101

Cialani, C. (2013). CO2 Emissions, GDP and Trade: A panel cointegration approach. Working Papers in Transport, Tourism, Information Technology and Microdata Analysis, (12), 1-19.

Copeland, B. R. and Taylor M. S. (1994). North-South trade and the environment, The Quarterly Journal of Economics, 109(3), 755-787. https://doi.org/10.2307/2118421

Çetin, M. ve Seker, F. (2014). Ticari açıklık ve finansal gelişmenin doğrudan yabancı yatırımlar üzerindeki etkisi: OECD ülkeleri üzerine dinamik 
panel veri analizi. Atatürk Üniversitesi İktisadi ve İdari Bilimler Dergisi, 28(1), 125-147.

Davidson, R. and MacKinnon, G. J. (1993). Estimation and Inference in Econometrics, Oxford University Press.

Değer, M. K. ve Pata, U. K. (2017). Türkiye'de dış ticaret ve karbondioksit salınımı arasındaki ilişkilerin simetrik ve asimetrik nedensellik testleriyle analizi. Doğuş University Journal, 18(1), 31-44.

Dougherty, C. (2007). Introduction to Econometrics, Oxford University Press Inc.

Farhani, S. and Ozturk, I. (2015). Causal relationship between CO2 emissions, real GDP, energy consumption, financial development, trade openness, and urbanization in Tunisia, Environmental Science and Pollution Research, 22(20), 15663-15676. https://doi.org/10.1007/s11356-0154767-1

Frankel, A. J. and Rose, K. A. (2005). Is trade good or bad for the environment? Sorting out the causality, Review of Economics and Statistics, 87(1), 8591. https://doi.org/10.1162/0034653053327577

Friedl, B. and Getzner, M. (2003). Determinants of CO2 emissions in a small open economy, Ecological Economics, 45(1), 133-148. https://doi.org/10.1016/S0921-8009(03)00008-9

Gujarati, N. D. (1988). Basic Econometrics, McGraw Hill International Edition.

Ibrahim, H. M. and Law, S. H. (2016). Institutional quality and CO2 emissiontrade relations: evidence from Sub-Saharan Africa, South African Journal of Economics, 84(2), 323-340. https://doi.org/10.1111/saje.12095

Kanberoğlu, Z., Arvas, M. A. ve Türkmenoğlu, M. (2017). Ekonomik büyüme, enerji tüketimi, ticari açıklık ve karbondioksitemisyon etkileşimi: Türkiye örneği. The Journal of Social Sciences Institute, 38, 273-286.

Karış, Ç. (2017). Türkiye'de enerji tüketimi, CO2 emisyonu ve ekonomik büyüme arasındaki ilişki: 1960-2013 Dönemi. Kocaeli Üniversitesi Sosyal Bilimler Dergisi, (34), 169-197.

Katırcıoğlu, S. T. (2014). International tourism, energy consumption, and environmental pollution: The case of Turkey, Renewable and Sustainable 


$\begin{array}{lrrr}\text { Energy } & \text { Reviews, } & \text { (36), } & \text { 180-187. }\end{array}$
https://doi.org/10.1016/j.rser.2014.04.058

Katırcıoğlu, S. T., Feridun, M., Kılınç, C. (2014). Estimating tourism-ınduced energy consumption and $\mathrm{CO} 2$ emissions: The case of Cyprus, Renewable and Sustainable Energy Reviews, (29), 634-640. https://doi.org/10.1016/j.rser.2013.09.004

Koçak, E. (2017). Finansal gelişme çevresel kaliteyi etkiler mi? Yükselen piyasa ekonomileri için ampirik kanttlar, Uluslararası Yönetim İktisat ve İşletme Dergisi, 13(3), 535-552. https://doi.org/10.17130/ijmeb.2017331326

Konyalılar, N. (2018). Sürdürülebilir otel paradigmasının, turizm işletmelerinde uygulanabilirliği üzerine bir araştırma, İstanbul Gelişim Üniversitesi Sosyal Bilimler Dergisi, 5(2), 91-107. https://doi.org/10.17336/igusbd.308247

Kukla-Gryz, A. (2009). Economic growth, international trade and air pollution: A decomposition analysis, Ecological Economics, 68(5), 329-1339. https://doi.org/10.1016/j.ecolecon.2008.09.005

Lee, C. C. and Chang, C. P. (2008). Tourism development and economic growth: A closer look at panels, Tourism Management, 29(1), 180-192. https://doi.org/10.1016/j.tourman.2007.02.013

León, J. C., Arana, E. J. and Alemán, H. A. (2014). CO2 emissions and tourism in developed and less developed countries, Applied Economics Letters, 21(16), 1169-1173. https://doi.org/10.1080/13504851.2014.916376

Mevzuat Fihrist. (n.d.). Çevre Kanunu. https://www.mevzuat.gov.tr/anasayfa/MevzuatFihristDetayIframe?Mev zuatTur=1\&MevzuatNo=2872\&MevzuatTertip $=5$

Ng, T. H., Chun T. L. and Ying S. L (2016). A decomposition analysis of CO2 emissions: Evidence from Malaysia's tourism industry, International Journal of Sustainable Development \& World Ecology, 23(3), 266-277. https://doi.org/10.1080/13504509.2015.1117534

Okutan Ş. ve Rahmi Y. (2018). Türkiye'nin Çevresel Kuznets Eğrisi: ARDL Sınır Testi Yaklaşımı. In H. F. Erdem ve A. Başoğlu (Ed.), İktisat seçme yazılar (pp. 157-182). Celepler Matbaacılık Yayın ve Dağıtım.

Öztürk, H. K., Öztürk, H. M. ve Dombayc1, Ö. A. (2018). Turizm sektöründe enerji tüketimi ve enerji tasarruf olanakları. Güncel Turizm Araştırmaları Dergisi, 2(1), 17-28. 
Paramati, S. R., Alam, M. S. and Chen, C.F. (2017). The effects of tourism on economic growth and $\mathrm{CO} 2$ emissions: A comparison between developed and developing economies, Journal of Travel Research, 56(6), 712-724. https://doi.org/10.1177/0047287516667848

Perrottet, J. and Benli, B. (2016, February 18). The Impact of Tourism: How Can We All Do This Better. The World Bank Blog, https://blogs.worldbank.org/psd/impact-tourism-how-can-we-all-dobetter

Peters, G. P. and Hertwich, E. G. (2008). CO2 embodied in international trade with implications for global climate Policy, Environmental Science and Technology, 42(5), 1401-1407. https://doi.org/10.1021/es072023k

Shahbaz, M., Loganathan, N., Muzaffar, A. T., Ahmed, K. and Jabran, M. A. (2016). How urbanization affects CO2 emissions in Malaysia? The application of STIRPAT Model, Renewable and Sustainable Energy Reviews, (57), 83-93. https://doi.org/10.1016/j.rser.2015.12.096

Solarin, S. A. (2014). Tourist arrivals and macroeconomic determinants of CO2 emissions in Malaysia, Anatolia, 25(2), 228-241. https://doi.org/10.1080/13032917.2013.868364

Tandoğan, D. ve Genç, M. C. (2016, Nisan 21-22). Turizm ve CO2 Emisyonu Arasindaki Illişki: Türkiye Örneği [Sözlü Sunum]. International Multidisciplinary Conference, Antalya. Türkiye. www.imuco.org

T.C. Dışişleri Bakanlığı. (n.d.). Küresel ısınma BM iklim değişikliği çerçeve sözleşmesi ve Kyto Protokolü. http://www.mfa.gov.tr/kuresel-isinmabm-iklim-degisikligi-cerceve-sozlesmesi-ve-kyto-protokolu.tr.mfa

Tümbek, A. N. (2010). Bütünleşik pazarlama faaliyetleri ile turizmin ve yabanc1 yatırımın ilişkilendirilmesi. Öneri Dergisi, 9(34), 173-194.

Zeren, F. (2015) Doğrudan yabancı yatırımların CO2 emisyonuna etkisi: kirlilik hale hipotezi mi kirlilik cenneti hipotezi mi?, Journal of Yasar University, 10(37), 6381-6477. https://doi.org/10.19168/jyu.97848 